\title{
Optimization of Drayage Operations with Time-Window Constraints
}

\author{
Samaneh Shiri and Nathan Huynh* \\ University of South Carolina \\ Department of Civil and Environmental Engineering \\ 300 Main Street, Columbia, SC 29208, USA \\ *Corresponding Author Contact Information \\ Nathan Huynh \\ University of South Carolina \\ Department of Civil and Environmental Engineering \\ 300 Main Street, Columbia, SC 29208, USA \\ Telephone: (803) 777-8947 \\ Fax: (803) 777-0670 \\ Email: nathan.huynh@sc.edu
}




\section{Introduction}

The focus of this paper is on port drayage, which refers to the movement of containers between a marine terminal and an inland distribution point or rail terminal. A typical drayage assignment involves either delivering an export container (full or empty) to a marine terminal or picking up an import container (full or empty) from a marine terminal. The time it takes a driver to complete one such assignment includes: (1) travel time to marine terminals, (2) inbound gate queue time, (3) inbound gate processing time, (4) container yard transaction time, (5) outbound gate queue time, (6) outbound gate processing time, (7) travel time to customers (or depots or rail terminals), and (8) transaction time at customer locations (or depots or rail terminals). Additional time is required when the driver must first pick up a chassis before picking up the import container or drop off the chassis after delivering the export container. Figure 1 illustrates how spread out the drayage operation can be. In this instance, the container and chassis operations are taking place in separate locations.

Despite the relatively short distance of the drayage movement compared to the rail or barge haul, drayage accounts for a large percentage of origin to destination expenses. Drayage cost as a portion of the total door-to-door cost varies according to the length of the trip. According to Morlok and Spasovic (1994), the drayage cost for 500 and 1,500-mile haul are 42\% and $22 \%$ of the total door-to-door cost, respectively. High drayage costs seriously affect the profitability of an intermodal service which in turn could impede the advance of intermodal freight transportation. Hence, it is important to improve drayage operations to keep costs low. Another important reason to improve drayage operations is to reduce its emissions impact on the surrounding communities due to engine idling and the stop-and-go lugging. Reducing the idling time of drayage trucks is equivalent to reducing local and regional particulate matter (PM 2.5), 
nitrogen oxides, and greenhouse gas emissions. Because drayage trucks operate primarily in urban environments, a reduction of these harmful pollutants has a proportionally greater benefit (Smith et al., 2012).

In an effort to reduce truck turn time and truck queuing at terminal gates, terminals such as those at the Port of Vancouver are requiring trucks to have an appointment system. The truck appointment system provides several key benefits to the terminal operators. One, it allows the terminal operators to match demands (container transactions) to supplies (labor and equipment availability). Second, it allows the terminal operators to evenly distribute truck arrivals throughout the day and hence reduce truck queuing at the gate. Lastly, the advanced entry of container and truck information via the appointment system expedites the processing of the trucks upon their arrivals to the terminal. While this new practice is beneficial to terminal operators and truckers, it poses a significant challenge to drayage firms who are already contending with a difficult drayage scheduling problem. Specifically, in addition to satisfying the need to pick or drop off a container at a customer location within a specified time window the drayage firms must also choose an appointment time window at the terminal such that it minimizes their operational costs.

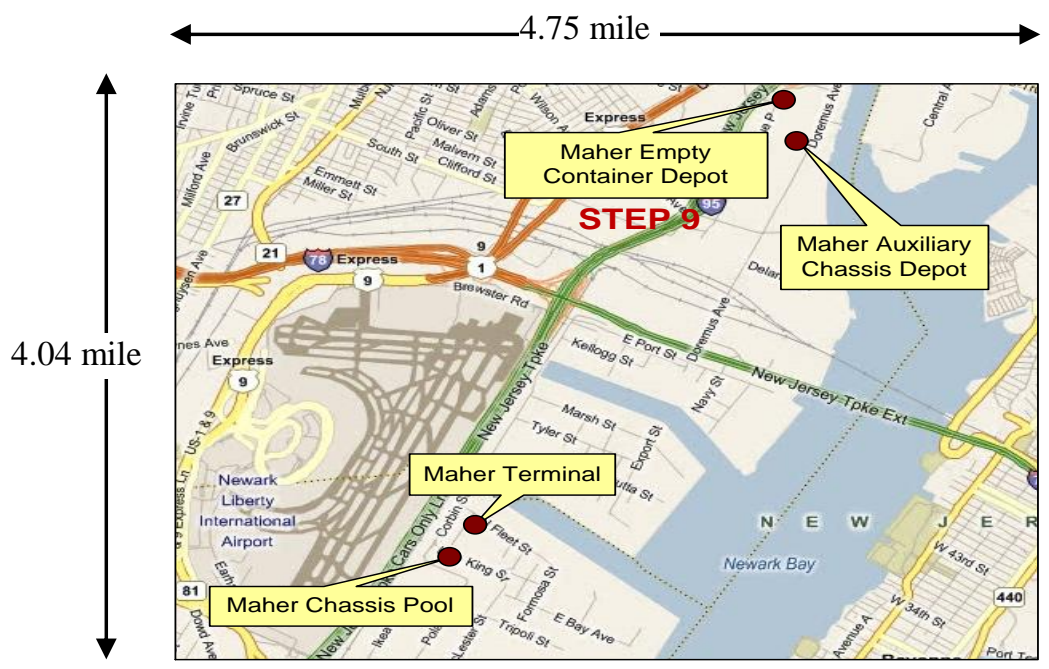

Figure 1 Layout of Maher container terminal and supporting depots at the Port of New York/New 
This paper aims to address the aforementioned emerging practice by developing a new mathematical model for the drayage scheduling problem with time window constraints (DSPTW) at customer locations and an appointment system at a marine container terminal. It assumes that all drayage operations use a single container type (i.e. 40-ft dry container) and that each truck carries a single container. The DSPTW is analogous to the multiple traveling salesman problem with time windows, but there are two key differences and challenges to modeling the DSPTW: (1) to complete a container transaction multiple locations may need to be visited, some of which are unknown a priori (e. g. the location of the empty container for the export-full transaction is not known a priori), and (2) the drayage firms need to book an appointment in advance prior to each visit to the container terminal. To solve the DSPTW, a reactive tabu search (RTS) algorithm is developed and its accuracy and computational efficiency is evaluated against an industry-established solver.

The rest of the paper is organized as follows. Section 2 provides a brief background on the drayage scheduling problem to provide context for this problem and to introduce a few relevant terminologies. Section 3 provides a review of related studies. Sections 4 provide the problem description and formulation. Section 5 presents the proposed solution methodology. Section 6 discusses the experimental results. Lastly, section 7 provides a summary of the study and concluding remarks.

\section{Background}

Figure 2 provides an overview of the relationships between strategic, tactical, and operational decisions and models that have been developed in the literature to manage in-land container movements. The drayage scheduling problem addressed in this paper pertains to the operational models. Specifically, it deals with the empty container allocation (reposition) model and routing 
model. The empty container allocation model deals with repositioning empty containers. Its goal is to determine the optimal distribution of empty containers based on the locations of demand and supply (i.e. customer locations, container terminal, empty container depot, and truck depot). For additional references pertaining to empty container management, readers are referred to Braekers et al. (2011). As illustrated in Figure 2, the output of the empty container allocation model is then used as input to the routing model, which aims to determine the optimal tour to satisfy the pickup and delivery orders of loaded and empty containers. The objective of the routing model is typically to minimize the overall operational costs of transporting loaded and empty containers.

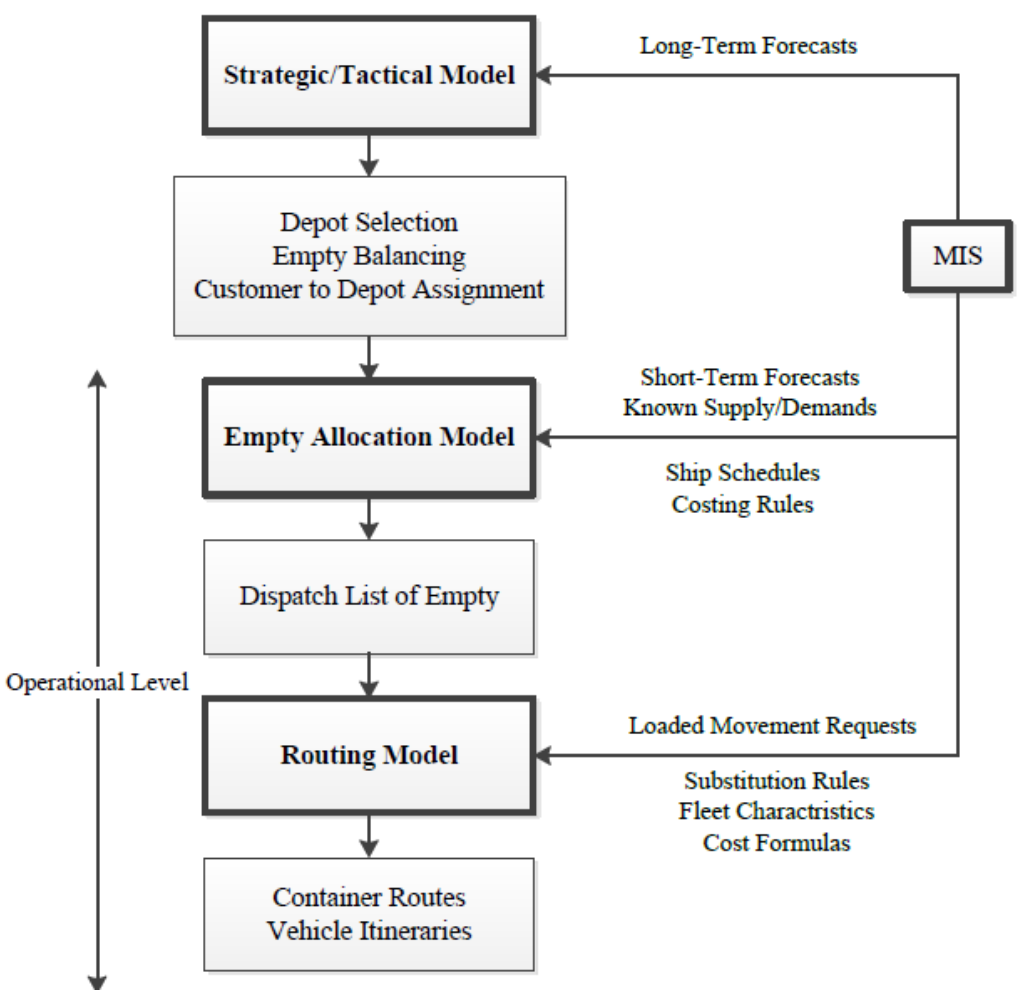

Figure 2 Overall planning approach of in-land container movements (adopted from Crainic et al., 1993). 


\section{Literature review}

Several studies have addressed the static and deterministic version of the drayage scheduling problem. Wang and Regan (2002) treated the drayage scheduling problem as a local truckload pickup and delivery problem and modeled it as an asymmetric multiple vehicle travelling salesman problem with time windows (am-TSPTW). They proposed a window partition-based method for solving the model. Jula et al. (2005) modeled the drayage scheduling problem as amTSPTW as well. They added a new constraint that addresses the hours-of-service regulation. They developed three solution approaches: (1) an exact algorithm based on dynamic programming, (2) a hybrid methodology that combines dynamic programming and genetic algorithm, and (3) an insertion heuristic method. Imai et al. (2007) solved the truckload pickup and delivery problem that involves an intermodal terminal. They proposed a relaxation-based heuristic which consists of two sub-problems: the classical assignment problem and the generalized assignment problem. Caris and Janssens (2009) extended the work of Imai et al. (2007) by introducing time window constraints at customer locations and the depot. Their solution approach employed a two-phase insertion heuristic to generate the initial solution; in phase one pickups and deliveries are combined into pairs and in phase two these pairs of customers are inserted into routes. This initial solution is further improved with a local search heuristic. Namboothiri and Erera (2008) studied the effect of a terminal appointment-based access control systems at a port on container pickup and delivery service operations. Their solution approach used a heuristic with column generation to generate near-optimal solutions. Xue et al. (2014) considered the drayage problem in which trucks do not wait at customers' locations during the packing and unpacking operations. They formulated the problem as a vehicle routing and scheduling problem with temporal constraints. Their solution method is 
based on tabu search. Both Popović et al. (2014) and Zhang et al. (2015) investigated the multisize container transportation problem. In the work by Popović et al. (2014), the authors proposed a variable neighborhood search heuristic to solve the problem. In the work by Zhang et al. (2015), the authors modeled the problem as a sequence-dependent multiple-traveling salesman problem with social constraints. They developed three tree search procedures and an improved reactive tabu search algorithm to solve the model. Their proposed search procedures can provide exact solutions for small-sized problems and their proposed reactive tabu search algorithm can solve realistic-sized problems efficiently.

In recent years, a number of studies have sought to solve the empty container allocation problem and vehicle routing problem in an integrated manner. Smilowitz (2006) modeled the integrated drayage scheduling problem as a multi-resource routing problem with flexible tasks. The author proposed a column generation method embedded in a branch-and-bound framework to solve the optimization model. Zhang et al. (2009) modeled the integrated drayage scheduling problem with multiple depots as am-TSPTW, and the authors solved it using a RTS algorithm. This work was extended by Zhang et al. (2010) who presented a window-partition based solution method inspired by Wang and Regan (2002). Zhang et al. (2011) built on their previous works and considered empty containers as transportation resources. They studied the integrated drayage scheduling problem where a single depot has a limited number of available empty containers. As in their past work, they utilized the RTS algorithm to solve their proposed model. Braekers et al. (2013) proposed a sequential and an integrated approach to solve the drayage problem. They developed a single-phase and a two-phase deterministic annealing algorithm to solve their proposed model. Their results showed that the integrated approach results are superior to those obtained by sequential approach. In their subsequent work, Braekers et al. 

(2) minimizing total distances. The problem is modeled as an asymmetric multiple vehicle traveling salesman problem with time windows. Three solution methods were developed to solve the model: (1) iterative, (2) deterministic annealing, and (3) hybrid of deterministic annealing and tabu search. They concluded that among the three methods the hybrid algorithm yielded the best results. Sterzik et al. (2015) investigated the effect of sharing empty container between trucking companies. They compared two scenarios: (1) trucking companies have access only to their own containers, and (2) trucking companies share empty containers between cooperating trucking companies. They proposed a tabu search heuristic to solve their proposed model. Their results showed that exchanging empty containers will yield lower total costs.

A few studies have addressed the dynamic and stochastic version of the drayage scheduling problem. Cheung and Hange (2003) assumed uncertainty in service times of tasks and formulated the problem as a stochastic model which seeks to minimize the current and future costs. To estimate the future costs the authors developed a time-window sliding procedure. Máhr et al. (2010) investigated the drayage scheduling problem with uncertainty in service-times and job-arrivals. They solved the problem by using an on-line optimization and an agent-based method. The on-line optimization method used a mixed integer program to obtain a new feasible route with newly captured information at 30 (s) intervals. The agent-based method used an auction scheme where container agents hold auctions in order of their arrivals and truck agents bid in these auctions. Zhang et al. (2011) studied the drayage scheduling problem where customer requests are not known a priori and developed a dynamic solution approach (the routing problem is solved at the beginning of the planning horizon and then updated at decision epochs). Real-time knowledge about the position of the vehicles is considered in the works by 
Escudero et al. $(2011,2013)$. Their solution approaches involved taking snapshots of prevailing situations, use the captured information to update the state of all tasks and vehicles, and then rerun the optimization model. Wang and Kopfer (2015) investigated the dynamic version of the drayage problem in which companies can exchange customer requests (i.e. dynamic collaborative transportation planning). They proposed two rolling horizon planning approaches to solve the problem. Their results showed that collaborative transportation planning yielded better results than isolated planning.

The focus of this study is most closely related to the work performed by Namboothiri and Erera (2008) in that both focus on solving the drayage scheduling problem with explicit consideration of the truck appointment system. However, the key differences between their work and ours are: (1) our model accounts for drayage firms with multiple depots, and (2) our model considers the empty container allocation problem, vehicle routing problem and appointment booking problem in an integrated manner. Our formulation adapts and extends the work of Zhang et al. (2010) to address the DSPTW. The key extension and contribution is the consideration of the truck appointment system and drayage scheduling problem jointly (to address the emerging practice as previously explained in the Introduction section). To our knowledge, our proposed model is the first to solve the empty container allocation problem, vehicle routing problem and appointment booking problem in an integrated manner. This integrated approach will allow for more accurate evaluation of the effects of the truck appointment system on drayage operational costs.

\section{Drayage problem description and formulation}

This study considers the typical drayage model in the U.S. That is, a drayage firm owns a number of trucks which are used to transport containers for customers. The containers and 
chassis are supplied by the ocean carriers. Depending on the size of the drayage firm, the truck fleet may be divided into several sub-fleets, each of which is managed by a dispatcher and the sub-fleets could be located in different truck depots. The job of the dispatcher is to manage the sub-fleet to satisfy the container transportation orders between the customers' locations, the empty container depot and the marine container terminal. The dispatcher's job is further complicated by the fact that customers operate on certain time windows and that the container terminal requires trucks to make appointments in advance. The scheduling decision to be made by the dispatcher on a daily basis is the focus of this study (i.e. solving the DSPTW).

In this study, a customer is the shipper or consignee. A loaded container to be transported from a shipper to the container terminal is called an export, and a loaded container to be transport from the container terminal to the consignee is called an import. Figure 3a shows a typical journey of one drayage truck. In this example, there is one container terminal, one truck depot with two trucks, one empty container depot, and two customers (one shipper and one consignee). The job orders involve fulfilling an import order for the consignee and an export order for the shipper. The sequence of the drayage movements are indicated by the respective numbers on the line segments in Figure 3a. The sequence begins with the truck picking up the import full container from the container terminal and then delivering it to consignee where the

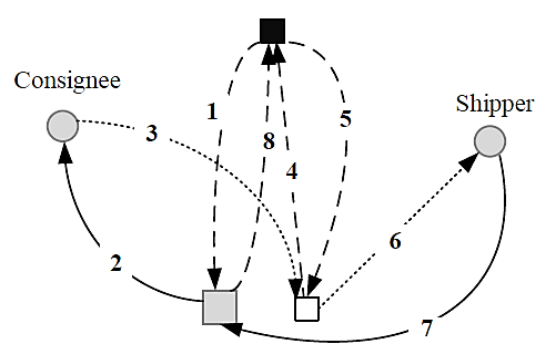

(a)

Customer's Location

Terminal

Empty container depot

Truck depot

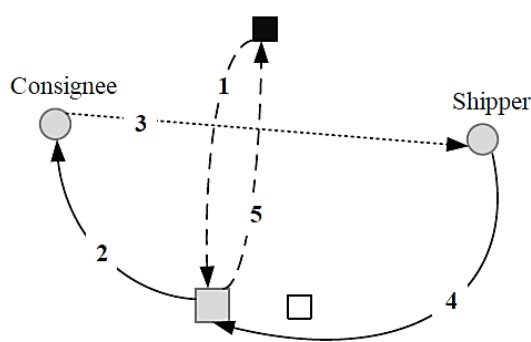

(b)

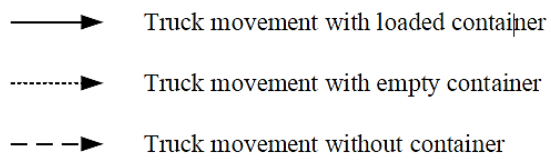

Figure 3 Illustration drayage truck movements: (a) without street turns; (b) with street turns. 
container will be unpacked (the container will then be empty). The truck then transports the empty container to the empty container depot and return to its truck depot. To fulfill the shipper's order, the truck first picks up the empty container from the empty container depot and then transports it to the shipper's location where the container will be packed (the container will then be full). The truck then transports the loaded container to the container terminal and returns to its truck depot. In this example, the empty containers are picked up from and delivered to the empty container depot, but it could also be done at the container terminal. Regardless of where the empty containers are stored, the mentioned drayage movements are still necessary.

It can be observed in the aforementioned example (Figure 3a) that the shipper will typically need an empty container before shipping a loaded container and thus it would be more efficient if the truck were to deliver the empty container from the consignee to the shipper. This strategy is known as "street-turns" and implementing such a strategy will result in fewer gate transactions at the container terminal or empty container depot, better driver productivity and enhanced equipment utilization. Figure $3 b$ illustrates the drayage movements for the same scenario using the street-turn strategy.

The aim of this study is to determine the optimal drayage sequence for each truck in a sub-fleet, considering street-turns, to fulfill all the transportation orders from customers. A customer is allowed to request one or more of the following jobs: import pickup and export delivery. In this study, we assume that trucks are required to stay at the customer's location during the packing and unpacking operation and one time window is considered at customer location. A similar assumption has been used in other studies, such as Zhang et al. (2010, 2011), and Escudero et al. $(2011,2013)$. However, it should be noted that if the packing and unpacking times are excessively long, then trucks will not stay at the customer locations. In that scenario, 
there will be two time windows at customer locations. An example study that uses this approach is the work by Xue et al. (2014). The considered time windows at customer location represents the time intervals in which the corresponding activities to customer location must be started. If a truck arrives at a customer location before the start of the specified time window, it must wait until that time window commences. Consequently, the total operation time includes travel, service and waiting time. This study models the truck appointment system the way that it is typically set up in practice in North American ports/terminals. That is, the appointment system is divided into multiple time periods in which the available number of quotas (i.e. number of trucks allowed) is predefined by the terminal operator. In current practice, the quota for each time period is applicable to both export and import containers. The drayage firms need to book appointments for trucks in advance (one day prior to dispatching a truck to the terminal). If the quota for the desired time period is exceeded, then they must choose a different time period. It is recognized that in other parts of the world (e.g. China), truck appointment systems (also known as vehicle booking systems) work differently and some are more advanced than the current stateof-the-practice in North America. For example, at some of these terminals, the operators set up the appointment system to coordinate truck arrivals with vessel schedules and not simply as a means to control truck entries. Examples of such works have been performed by Chen et al. (2010) and Chen and Yang (2010).

The drayage firm is considered to have multiple truck depots in which a limited number of trucks are located initially. All trucks must start at and return to one of these truck depots. The final truck depot does not have to be the same as the starting truck depot. We assume that trucks will choose the depot nearest to their last location as the final depot. We assume that all containers (empty and full) are of the same type (40-ft dry containers) and that empty containers 
are stored in the empty container depot and should be picked up from and delivered to this depot.

It is assumed that there is a sufficient number of empty containers at the empty container depot.

\subsection{Problem parameters}

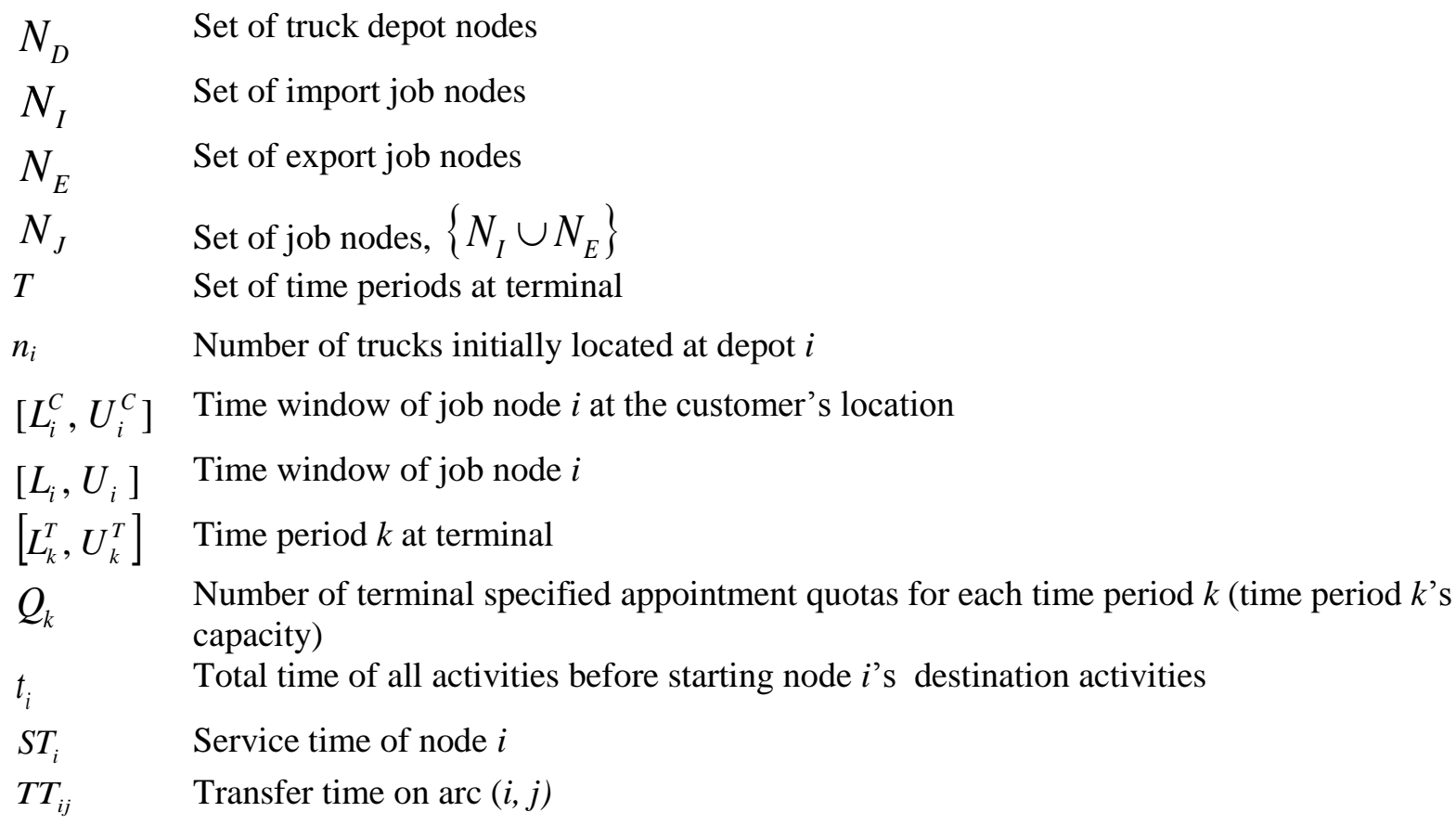

\subsection{Graphical representation of the drayage problem}

The formulation of the DSPTW is based on a graph representation of the various drayage activities. This graphical representation is adapted from the work of Zhang et al. (2010) which is an activity-based graph. Consider a network that is represented by a directed graph with a set of $N$ nodes and a set of $A$ arcs. The $N$ nodes consist of either a depot node or a job node. A depot node $\left(N_{D}\right)$ specifies the number of trucks at the truck depot, denoted by $n_{i}$. A job node is defined as a series of activities that should be performed for each type of job, import pickup $\left(N_{I}\right)$ or export delivery $\left(N_{E}\right)$. The job node includes the travel time between the container terminal and customer location, time to mount/unmount the container at the customer location, time to pack/unpack the container at the customer location, time to pick up/drop off the container at the terminal, and time waiting in queue at the terminal gate. The time it takes to complete all of 
these activities is called the service time $\left(S T_{i}\right)$. The activity and time associated with import and export job nodes are provided in Table 1.

Table 1 Activity and time associated with import and export job nodes.

\begin{tabular}{ll}
\hline Job Node $i$ & Activity and Time \\
\hline \multirow{2}{*}{$\begin{array}{l}\text { 1. Pick up import container at terminal (terminal turn time). } \\
\text { 2. Transport container to customer (travel time between terminal and customer's location). }\end{array}$} & 3. Unmount full container from truck (time to unmount container). \\
& 4. Customer unpack container (unpack time). \\
& 5. Mount empty container to truck (time to mount container). \\
\hline \multirow{2}{*}{$\begin{array}{l}\text { 1. Unmount empty container from truck (time to unmount container). } \\
\text { 2. Customer pack container (time to pack container). }\end{array}$} & $\begin{array}{l}\text { 3. Mount full container to truck (time to mount container). } \\
\text { 4. Transport loaded container to terminal (travel time between customer's location and terminal). }\end{array}$ \\
5. Wait in queue at terminal gate (gate queuing time). \\
6. Drop off export container at terminal (terminal turn time).
\end{tabular}

For each job node, the attribute $t_{i}$ is defined as the total time it takes to complete all of the activities prior to arriving to the destination of that job. For the import job node, the destination is the consignee's location, and thus, $t_{i}$ is the combined time associated with activities 1 and 2. For the export job node, the destination is the container terminal and thus, $t_{i}$ is the combined time associated with activities 1, 2, 3, 4 and 5 .

Another attribute of the job nodes is the time windows, denoted by $\left[L_{i}, U_{i}\right]$. The interval $\left[L_{i}^{C}, U_{i}^{C}\right]$ indicates that the activities for a job should start within this time interval at the customer's location. For the export job node, activity 1 must start within the interval $\left[L_{i}^{C}, U_{i}^{C}\right]$; thus, the job node's time window $\left[L_{i}, U_{i}\right]$ is equal to the customer location time window $\left[L_{i}^{C}, U_{i}^{C}\right]$. For the import job node, the activity 3 must start within the interval $\left[L_{i}^{C}, U_{i}^{C}\right]$. To meet this time window requirement, activity 1 must start within time interval $\left[L_{i}^{C}-t_{i}, U_{i}^{C}-t_{i}\right]$. Consequently, the import job node's time window $\left[L_{i}, U_{i}\right]$ is equal to $\left[L_{i}^{C}-t_{i}, U_{i}^{C}-t_{i}\right]$. 
Table 2 Transfer time for all possible combination of activities at node $i$ and node $j$.

\begin{tabular}{|c|c|c|c|c|}
\hline \multirow{2}{*}{\multicolumn{2}{|c|}{$T T_{i j}$}} & \multicolumn{3}{|c|}{ To node $j$} \\
\hline & & $N_{D}$ & $N_{I}$ & $N_{E}$ \\
\hline \multirow{3}{*}{$\begin{array}{r}1 \\
\vdots \\
\vdots \\
\vdots \\
\vdots \\
\vdots \\
\vdots \\
1 \\
2\end{array}$} & $N_{D}$ & - & $\begin{array}{l}\text { 1. Travel time between truck } \\
\text { depot and terminal. } \\
\text { 2. Gate queuing time. }\end{array}$ & $\begin{array}{l}\text { 1. Travel time between truck } \\
\text { depot and empty container } \\
\text { depot. } \\
\text { 2. Time to mount container. } \\
\text { 3. Travel time between empty } \\
\text { container depot and customer. }\end{array}$ \\
\hline & $N_{I}$ & $\begin{array}{l}\text { 1. Travel time between } \\
\text { customer and empty } \\
\text { container depot. } \\
\text { 2. Time to unmount container. } \\
\text { 3. Travel time between empty } \\
\text { container depot and truck } \\
\text { depot } j \text {. }\end{array}$ & $\begin{array}{l}\text { 1. Travel time between } \\
\text { customer } i \text { and empty } \\
\text { container depot. } \\
\text { 2. Time to unmount container. } \\
\text { 3. Travel time between empty } \\
\text { container depot and } \\
\text { terminal. } \\
\text { 4. Gate queuing time. }\end{array}$ & $\begin{array}{l}\text { If node } i \text { customer is different } \\
\text { from node } j \text { customer: } \\
\text { Travel from customer } i \text { to } \\
\text { customer } j \text {. } \\
\text { Otherwise: } \\
\text { No activity }\end{array}$ \\
\hline & $N_{E}$ & $\begin{array}{l}\text { 1. Travel time between } \\
\text { terminal and truck depot } j \text {. }\end{array}$ & No activity & $\begin{array}{l}\text { 1. Travel time between terminal } \\
\text { and empty container depot. } \\
\text { 2. Time to mount container. } \\
\text { 3. Travel time between empty } \\
\text { container depot to customer } j \text {. }\end{array}$ \\
\hline
\end{tabular}

The arc $(i, j)$ represents the transfer time between the completion of node $i$ activities and the commencement of node $j$ activities. The transfer time on arc $(i, j)$ depends on the combination of depot and job nodes that occur at $i$ and $j$. The transfer time for all possible combinations is provided in Table 2. Note that there is "No activity" for the $N_{E}$ and $N_{I}$ combination because the truck would be at the container terminal at the completion of job $N_{E}$ and thus it is at the location of where it needs to be to commence job $N_{I}$. There is also "No activity" for the $N_{I}$ and $N_{E}$ combination when customer $i$ and $j$ are the same; in this scenario, the truck would drop off the import container and then pick up the export container at the same location. The $N_{D}$ to $N_{D}$ combination is not considered since it is unlikely to occur in practice.

Figure 4 provides the graph representation of the drayage example problem discussed previously, along with illustrative node and arc attributes. The truck depot is represented by node $1, N_{D}=\{1\}$. With two trucks starting from node $1, n_{1}=2$. The job orders for the 
consignee and shipper are represented by the job nodes 2 and 3 , respectively; $N_{J}=\{2,3\}, N_{I}=$ $\{2\}, N_{E}=\{3\}$. Based on the activity times associated with the job orders (see Table 1), the service times $S T_{1}$ and $S T_{2}$ and time windows $\left[L_{1}, U_{1}\right]$ and $\left[L_{2}, U_{2}\right]$ for $N_{I}$ and $N_{E}$ can be computed. The transfer times between nodes are represented by the arcs, which can be computed based on the from-to node combinations (see Table 2).

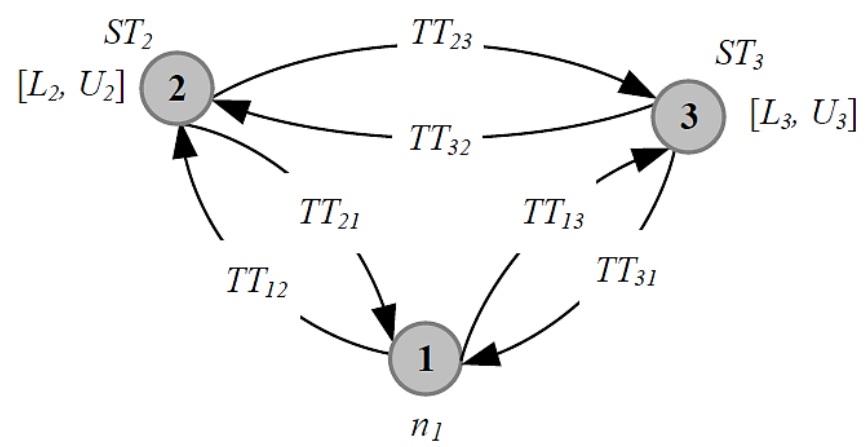

Figure 4 Graph representation of the drayage example illustrated in Figure 3.

\subsection{Mathematical formulation}

The mathematical formulation of the DSPTW is based on the graphical representation presented in the previous section. Its decision variables, objective function, and constraints are presented below.

$x_{i j}= \begin{cases}1 & \text { If } \operatorname{arc}(i, j) \text { is included in the solution } \\ 0 & \text { Otherwise }\end{cases}$

$q_{i k}= \begin{cases}1 & \text { If customer } i \text { books an appoinment in time period } k \\ 0 & \text { Otherwise }\end{cases}$

$s_{i}=$ Time that the first activity on node $i$ is started.

$p_{i}=$ Truck arrival time at terminal gate to start terminal related activities of node $i$.

$$
\min \sum_{i \in N_{J}} \sum_{j \in N_{D}} s_{i} \times x_{i j}-\sum_{i \in N_{D}} \sum_{j \in N_{J}} s_{j} \times x_{i j}+\sum_{i \in N_{D}} \sum_{j \in N_{J}} T T_{i j} \times x_{i j}+\sum_{i \in N_{J}} \sum_{j \in N_{D}}\left(S T_{i}+T T_{i j}\right) \times x_{i j}
$$




$$
\begin{array}{ll}
\sum_{j \in N_{J}} x_{i j} \leq n_{i} & \forall i \in N_{D} \\
\sum_{i \in N_{D} \cup N_{J}} x_{i j}=\sum_{i \in N_{D} \cup N_{J}} x_{j i}=1 & \forall j \in N_{J} \\
s_{i}+S T_{i}+T T_{i j}-\left(1-x_{i j}\right) \times M \leq s_{j} & \forall i, j \in N_{J} \\
T T_{i j}-\left(1-x_{i j}\right) \times M \leq s_{j} & \forall i \in N_{D}, \forall j \in N_{J} \\
L_{i} \leq s_{i} \leq U_{i} & \forall i \in N_{J} \\
p_{i}=s_{i} & \forall i \in N_{I} \\
p_{i}=s_{i}+t_{i} & \forall i \in N_{E} \\
p_{i}-M \times\left(1-q_{i k}\right) \leq U_{k}^{T} & \forall k \in T, \forall i \in N_{J} \\
p_{i}+M \times\left(1-q_{i k}\right) \geq L_{k}^{T} & \forall k \in T, \forall i \in N_{J} \\
\sum_{k \in T} q_{i k}=1 & \forall i \in N_{J} \\
\sum_{i \in N_{J}} q_{i k} \leq Q_{k} & \forall k \in T
\end{array}
$$

Equation (1) is the objective function which seeks to minimize the drayage operation time. The first term of the objective function is the start times of the trucks' last jobs prior to returning to the truck depot. The second term is the start times of the trucks' first jobs after leaving the truck depot. The difference between these two terms represents the operation time of all trucks between their first and last jobs. The third term is the transfer time between the truck depot and the location of trucks' first jobs. The fourth term is the service time of the trucks' last jobs and transfer time between the location of these jobs and the nearest truck depot. Constraint (2) is the capacity constraint for truck depots which ensures that the number of routes started from each truck depot is less than or equal to the initial number of trucks at that depot. 
Constraint (3) states that each job node should be visited exactly once. Constraints (4) and (5) enforce the time relationship of consecutive nodes along a route. Constraint (6) restricts the start time of job nodes to their time windows. Constraints (7) and (8) compute the arrival time of the truck to the terminal gate. Constraints (9) and (10) determine the time period at which a truck should book an appointment based on the truck arrival time at the terminal gate (computed by constraints (7) and (8)). Constraint (11) ensures that only one appointment is booked for each job node. Constraint (12) limits the number booked appointments in each time period to the specified quota for that time period (i.e. the time period capacity cannot be exceeded).

\section{Solution methodology}

The proposed mathematical model is NP-hard since it is an extension of the NP-hard problem mTSPTW and meta-heuristics are widely used to solve similar problems. The proposed solution methodology in this work is based on the RTS algorithm (Battiti and Tecchiolli, 1994). While a number of meta-heuristics could be used to solve the proposed model, RTS is used in this study because it has been found to be successful in solving drayage problems (Zhang et al., 2009, 2011, 2015), as well as vehicle routing problems (Chiang and Russell, 1997; Osman and Wassan, 2002; Wassan et al., 2008). The solution method consists of two phases. Phase 1 generates an initial solution via a greedy heuristic and phase 2 seeks to obtain the optimal solution via the RTS. Figure 5 provides an overview of the developed solution methodology. 


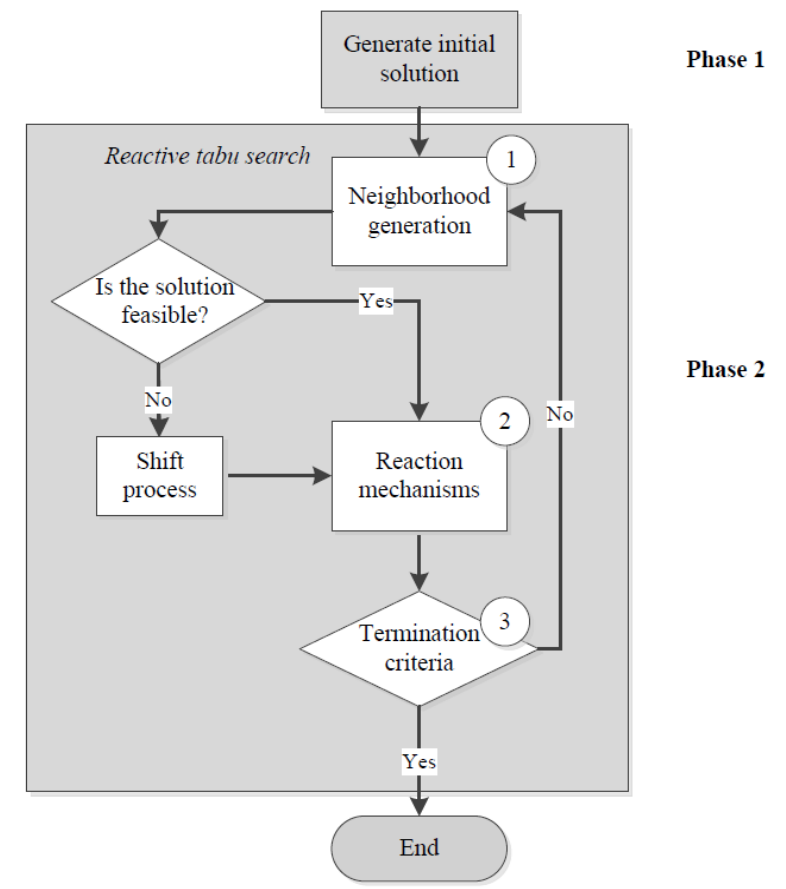

Figure 5 Flowchart of developed solution methodology.

\subsection{Initial solution generation procedure}

Phase 1 uses a greedy heuristic to generate an initial solution. The heuristic involves adding job nodes one at a time to a feasible route that yields the lowest cost route from a depot node by using Eq. 1. Each time a route is constructed from a depot node the number of trucks at that depot is decreased by one. The procedure continues to add the lowest-cost unassigned job node until no job can be further added to this route while satisfying constraints (6), (11), and (12), as well as (13) through (18). At this point, the truck should return to one of truck depots and the heuristic selects the depot nearest to its last job node. This process is repeated until all job nodes are assigned to routes or no more route can be created. If there are trucks that are not used in the solution, their corresponding depot nodes are inserted at the end and empty routes are constructed. If the number of trucks or appointment quotas is not sufficient, then the initial solution could be infeasible. In these cases, unassigned job nodes are kept in a set and the RTS will start with an infeasible initial solution. 
Figure 6 provides the pseudo codes for the greedy heuristic, which uses the following variables and definitions.

$$
\begin{aligned}
& s_{j}=\max \left\{T T_{i j}, L_{j}\right\}, \forall i \in N_{D}, \forall j \in N_{J} \\
& s_{j}=\max \left\{s_{i}+T T_{i j}+S T_{i}, L_{j}\right\}, \forall i, j \in N_{J} \\
& k=\arg \underset{\substack{k \in T \text { with } \\
\text { nonzero oremining capacity } \\
\text { and } p_{i}>L_{k}^{T}}}{\min }\left\{L_{k}^{T}\right\} \\
& p_{j}=\max \left\{L_{k}^{T}, p_{j}\right\} \\
& j=\arg \min _{j \in U A}\left\{T T_{i j}\right\}, \forall i \in N_{D}, \forall j \in N_{J} \\
& j=\arg \min _{j \in U A}\left\{s_{j}\right\}, \forall i, j \in N_{J}
\end{aligned}
$$

where $U A$ is the unassinged job node set and $i$ is the from node and $j$ is the to node.

In Figure 6, the outer until loop generates routes from a depot node, and the inner until loop adds job nodes to this route until no more job nodes can be further added to this route. A solution $S$ is represented by a set of truck routes, $S=\left\{R_{1}, R_{2}, \ldots, R_{v}\right\}$ with $v$ being the total number of trucks in all truck depots. For the problem shown in Figure 4, the solution is represented by $S=\left\{R_{1}, R_{2}\right\}$ and a possible solution is $R 1=\{1,2,3\}$ and $R 2=\{1\}$. The values in the set $R_{l}$ indicate that a truck will depart from the truck depot (node 1) and then go to job nodes 2 and 3. $R_{2}$ consists only of node 1 which implies that the second truck will remain at the depot node and thus this is an empty route. 
until (all job nodes are assigned to routes or no more route can be created)

for all $i \in N_{D}$ with nonzero capacity

for all $j \in U A$

Calculate $s_{j}$ using (13)

if $j \in N_{I}$

$$
\begin{aligned}
& \text { Calculate } p_{j} \text { using (7) } \\
& \text { else }
\end{aligned}
$$

Find the lowest-cost job node

Reduce trucks number in depot $i$ and time period $k$ 's capacity by one $i \leftarrow j$

until no more insertion is valid

for all $j \in U A$

Calculate $s_{j}$ using (14)

if $j \in N_{I}$

Calculate $p_{j}$ using (7)

else

Calculate $p_{j}$ using (8)

end

Find the time period $k$ that an appointment can be booked using (15)

Recalculate $p_{j}$ using (16)

if $j \in N_{I}$

Recalculate $s_{j}$ using (7)

else

Recalculate $s_{j}$ using (8)

end end

Find the lowest-cost job node using (6) and (18)

Reduce time period $k$ 's capacity by one end

end

Figure 6 Initial solution's algorithm.

\subsection{Reactive tabu search}

Tabu search (TS) is a memory based metaheuristic which uses neighborhood search and prohibition-based techniques. During the exploration process, a collection of solutions are created by a set of moves that transforms one solution into another. A collection of adjacent solutions that can be reached from a solution is called a neighborhood. TS prevents cycling back 


\subsubsection{Neighborhood generation}

RTS explores the solution space by moving from a solution $S$ to an adjacent solution $S^{\prime}$. That is, through the neighborhood generation mechanism (step 1 of phase 2 shown in Figure 5) the neighborhood of the current solution $N(S)$ is generated at each iteration; the number of neighborhood solutions to be generated is equal to the specified maximum neighborhood size parameter. Then, the best solution in the neighborhood is selected, even if it is worse than the current solution, as the new current solution, and the procedure is repeated. The neighborhood generation mechanism used in this paper is the $\lambda$-interchange mechanism introduced by Osman (1993) which exchanges a subset of job nodes between routes to generate a neighboring solution. We implemented $\lambda$-interchange mechanism with $\lambda=1$ which works as follows.

Let $S=\left\{R_{1}, R_{2}, \ldots, R_{v}\right\}$ be a solution. First, two routes are selected from the solution $S$ randomly, say $R_{p}$ and $R_{q}$. Then two subsets of nodes $\left(S_{p}\right.$ and $\left.S_{q}\right)$ are chosen from the nodes in $R_{p}$ and $R_{q}: S_{p} \subseteq R_{p}$ and $S_{q} \subseteq R_{q}$. The 1-interchange mechanism exchanges a subset of $S_{p}$ of size 
$\left|S_{p}\right| \leq 1$ from $R_{p}$ with a subset of $S_{q}$ of size $\left|S_{q}\right| \leq 1$ from $R_{q}$ and thus generates two new routes, $R_{p}^{\prime}$ and $R_{q}^{\prime}$, and a new solution $S^{\prime}$. This mechanism invokes two processes to generate neighboring solutions, shift and interchange processes:

- A shift process is represented by $(1,0)$ or $(0,1)$ operators. These operators move one job node from a route to another route. For instance, the $(1,0)$ operator removes one job node from route $R_{p}$ and adds it to route $R_{q}$.

- An interchange process is represented by the $(1,1)$ operator which exchanges one job node between routes $R_{p}$ and $R_{q}$.

Note that with the interchange process the length of the route is not changed, whereas with the shift process the $(0,1) /(1,0)$ operator will increase/decrease the length of route $R_{p}$ and decrease/increase the length of route $R_{q}$ by one. Furthermore, for the interchange process one job node is selected from each of the two randomly selected routes, and similarly for the shift process one job node is selected from one of the two selected routes. For both the shift and interchange processes, the selected job nodes are inserted in the best position on the other routes.

To improve the quality of the solution, this study also implemented a mechanism called Local-shift introduced by Wassan et al. (2008). This mechanism is used after the $\lambda$-interchange mechanism, and it is applied to the routes which were altered by the $\lambda$-interchange mechanism. The Local-shift relocates a job node to a different position within the route, if such a move improves the solution. To generate adjacent solutions, all three neighborhood generation mechanisms are used at each iteration. Each time that a new solution is obtained, the tabu status of the corresponding moves and the feasibility of the solution are checked and the solution is evaluated using Eq. 1. If the algorithm starts with an infeasible initial solution, then at each iteration when the new solution is found (after the neighborhood generation step) the shift 
process will then be used to check the feasibility of moving some or all of the unassigned jobs to the new solution. The maximum neighborhood size used for experiment 1 to 8 is 200 , experiment 9 to 15 is 1000 , and experiment 16 to 27 is 2000 .

\subsubsection{Reaction mechanisms}

The history of visited solutions can affect the search path in RTS algorithm (step 2 of phase 2 shown in Figure 5). RTS tracks the frequency of revisiting solutions to adjust the search trajectory with two reaction mechanisms. Figure 7 provides the algorithmic steps involved in the reaction mechanism. These mechanisms are briefly explained below.

1. The tabu tenure $(t t)$ is dynamically controlled. If a solution is repeated within a predefined number of iterations (CYCLE_MAX), then it means that the algorithm is falling into a cycle. In this case, the tabu tenure is increased by a predetermined factor INC where INC $>1$ (step 3 in Figure 7). Moreover, a moving average (movingAverage) of detected cycles is calculated during the search procedure. If number of iterations passed from last change of tabu tenure is more than this moving average, then the tabu tenure is decreased by a predetermined factor $D E C$ where $0<D E C<1$ (step 4 shown in Figure 7). Each time that the tabu tenure is updated it is rounded up to the next integer.

2. If a solution is repeated more than $R E P$ times ( $R E P$ is a predefined parameter), then that solution is considered as an often-repeated solution (step 2 in Figure 7). If the number of often-repeated solutions is more than CHAOS (CHAOS is a predefined parameter), then it can be concluded that the search is confined to an attractor basin. In this case, RTS will use the escape mechanism to get out of the basin. The escape mechanism clears the tabu list and performs successive random moves. This mechanism will change the makeup of the solution and move the search into a different region of the solution space. 
Step 0: Initialization of reaction mechanisms parameter. repeat $=0$ (Number of iterations that a solution has been visited) chaotic $=0$ (Number of often-repeated solutions) movingAverage $=0$ (Moving average of the iteration intervals between detected cycle) changeInterval $=0$ (Number of iterations passed after last change in tabu tenure value) revisitInterval $=0$ (Number of iteration between current and previous occurrence of a solution) $t t=5$ : tabu tenure value

$R E P=3$

CHAOS $=6$

INC $=1.1$

$D E C=0.9$

CYCLE_MAX $=50$

\section{Step 1:}

Search for the current solution $(S)$ in the hash matrix

if $S$ found in the hash matrix

revisitInterval $=$ number of iteration between current and previous occurrence of $S$

repeat $=$ repeat +1

else

Add $S$ to hash matrix

Go to Step 4

end

Step 2:

if repeat $>R E P$

repeat $=0$

chaotic $=$ chaotic +1

else

Go to Step 3

end

if chaotic > CHAOS

chaotic $=0$

Execute escape mechanism

Stop

else

Go to Step 3

end

Step 3:

if revisitInterval $<C Y C L E \_M A X$

$t t=t t \times I N C$

changeInterval $=0$

movingAverage $=0.1 \times$ revisitInterval $+0.9 \times$ movingAverage

Stop

else

Go to Step 4

end

Step 4:

if changeInterval > movingAverage

$t t=t t \times D E C$

changeInterval $=0$

Stop

else

changeInterval $=$ changeInterval +1

Stop

end

Figure 7 Reaction mechanism. 


\subsubsection{Termination criteria}

The developed algorithm is terminated after a certain number of iterations (step 3 of phase 2 shown in Figure 5) which is defined based on the size of the problem. Our algorithm is terminated after performing $50 \times n$ iterations where $n$ is total number of nodes.

\subsubsection{RTS components}

Tabu list: In this study, the data structure used to store the tabu list is called $T A B L$, which is adopted from work of Chiang and Russell (1997). TABL is a matrix with $n$ rows and $v$ columns ( $n$ is the number of job nodes and $v$ is the number of routes). The matrix $T A B L$ is initialized with high negative values. TABL $(i, p)$ records the iteration number at which job node $i$ was removed from route $R_{p}$. Suppose at iteration $k$, job node $i$ is a candidate to move to the route $R_{p}$. This move is classified as tabu if:

$k-\operatorname{TABL}(i, p)<t t$

Hashing function: RTS requires a method to compare the obtained solution with previously visited solutions and determine if a solution has been visited or not, and if yes, how long ago. Considering the number and size of the solutions, storing all characteristics of visited solutions and comparing a new solution with all visited solutions is computationally expensive and memory-consuming. To identify previously visited solutions, representative information of visited solutions can be used as a solution identity. In this study, a solution identity is its hash value calculated from the following hashing function proposed by Woodruff and Zemel (1993):

Hash value $=\left[\sum_{i=1}^{n} z\left(x_{i}\right) z\left(x_{i+1}\right)\right] \bmod [$ MAXINT +1$]$

where:

$n=$ the cardinality of set $X$,

$X=$ a solution vector, where $x_{i} \in X$ for $i=1 . . n$ (since length of vector $X$ is $n, x_{n+1}$ is not defined. So, $x_{n+1}$ will be replaced by $x_{1}$ when $i=n$ ), 
$\mathrm{Z}=\mathrm{a}$ vector of pre-generated values between $1 \ldots m$, where $z_{i} \in Z$ for $i=1 . . n$ ( $m$ is a big number), and

MAXINT $=$ the maximum integer that can be represented by the computer.

Hash values associated with each solution are stored in a matrix called hash matrix. Each row of the hash matrix is related to a solution which stores the solution's hash value along with the number of repeated visits and the last iteration that visit occurred. Each time a new solution is obtained its hash value is searched in the hash matrix. If it is not found, then this solution is added to the hash matrix. Otherwise, the number of repeated visits is increased by one and the iteration of the last visit is updated to the current iteration.

\section{Numerical analysis}

To demonstrate the feasibility of the developed model and solution methodology, they are tested on randomly generated instances with real life characteristics. Instances are generated on a hypothetical network shown in Figure 8 with one container terminal, one empty container depot and two truck depots. The size of the network is chosen to be sufficiently large; in particular, the travel time along the edges of the network is chosen to be 3 hours. The container terminal and the empty container depot are 10 minutes apart. The customer locations are generated randomly within the network. The time to mount/unmount the container is assumed to be 5 minutes (Chung et al., 2007). Packing/unpacking times are assumed to be uniformly distributed with a minimum of 5 minutes and a maximum of 60 minutes, $U(5,60)$ (Zhang et al., 2010). Lower bound of time windows are assumed to be uniformly distributed in the range of 0 (8:00 A.M.) to 240 (12:00 P.M.) and the upper bound is calculated according to the width of the time window. The width of the time window is assumed to be 240 minutes. Chen et al. (2013) considered five target levels for the average gate queueing time: $2,5,10,15$, and 20 minutes. In this study, a 
queueing time of 10 minutes is assumed, except for those experiments shown in Table 6. The container terminal is assumed to operate 10 hours each day and there are a total of 10 time periods (i.e. $T=10$ ). Appointment quotas in each time period are assumed to be uniformly distributed with a minimum of 0 and a maximum of the number of job nodes divided by $3, \mathrm{U}(0$, number of job nodes/3).

The developed mathematical formulation is a mixed-integer quadratic programming model (MIQP). To obtain the exact solutions to validate our model and solution methodology, we used the commercial solver CPLEX (version 12.6); note that this version of CPLEX is capable of solving MIQP models. The solution methodology, RTS, was coded in MATLAB R2012b. The experiments were conducted on a desktop computer with a $3.40 \mathrm{GHz}$ processor and 16 GB of RAM. This study used the RTS parameter values suggested by Osman and Wassan (2002) as a starting point. These parameters were then systematically adjusted and finetuned such that the RTS gives the same optimal solution as CPLEX for small-sized and some

medium-sized problems.
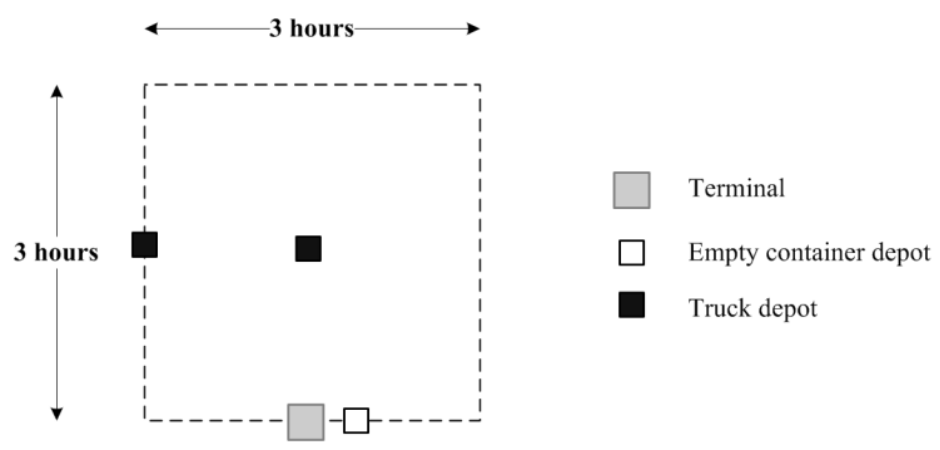

Figure 8 Illustration of hypothetical network.

The results for small to medium-sized problems are provided in Table 3. The first column shows the experiment number. The second column shows the problem size in terms of number of job nodes. The third and fourth columns show the objective function values and computation time of CPLEX, respectively. The results obtained from the developed solution 
methodology (RTS) are reported in the fifth, sixth and seventh columns. The fifth column shows the objective function value of the initial feasible solution. The sixth column shows the RTS objective function value, and the seventh column shows the RTS computation time. The last column shows the gap between the CPLEX and RTS solutions. As indicated by the gap values, RTS yields the same optimal solutions as CPLEX for 17 experiments out of 19 small and medium-sized problems. RTS was not able to produce the same optimal solutions for experiments 18 and 19 which had 35 and 40 job nodes. However, RTS was able to obtain nearly the same solution (gap of less than 3.72\%) in a fraction of the computation time (8.55 minutes for RTS vs. 25.39 hours for CPLEX). It should be noted that the reported computation time for RTS is based on its implementation in the MATLAB environment. It is expected that the computation time will be much less if the RTS algorithm is implemented in a lower-level programming language such as $\mathrm{C}++$. 
Table 3 Comparison of RTS performance against CPLEX for small and medium-sized problems.

\begin{tabular}{|c|c|c|c|c|c|c|c|}
\hline (1) & (2) & (3) & (4) & (5) & (6) & (7) & (8) \\
\hline \multirow{3}{*}{$\begin{array}{c}\text { Experiment } \\
\text { No. }\end{array}$} & \multirow{3}{*}{$\begin{array}{c}\text { Problem } \\
\text { size }\end{array}$} & \multicolumn{2}{|c|}{ CPLEX } & \multicolumn{3}{|c|}{ Solution method } & \\
\hline & & & & $\begin{array}{c}\text { Initial } \\
\text { feasible } \\
\text { solution }\end{array}$ & RTS & & \\
\hline & & $\begin{array}{l}\text { Objective } \\
\text { value }\end{array}$ & Time (s) & $\begin{array}{l}\text { Objective } \\
\text { value }\end{array}$ & $\begin{array}{c}\text { Objective } \\
\text { value }\end{array}$ & $\begin{array}{c}\text { Time } \\
\text { (s) }\end{array}$ & $\begin{array}{r}\text { Gap }^{1} \\
(\%)\end{array}$ \\
\hline 1 & 2 & 517 & 0.01 & 517 & 517 & 2.5 & 0 \\
\hline 2 & 3 & 856 & 0.01 & 899 & 856 & 4.23 & 0 \\
\hline 3 & 4 & 871 & 0.12 & 1104 & 871 & 5.98 & 0 \\
\hline 4 & 5 & 1112 & 0.13 & 1485 & 1112 & 6.818 & 0 \\
\hline 5 & 6 & 1126 & 0.30 & 1303 & 1126 & 9.39 & 0 \\
\hline 6 & 7 & 1253 & 0.36 & 1469 & 1253 & 11.67 & 0 \\
\hline 7 & 8 & 1660 & 0.47 & 2143 & 1660 & 12.82 & 0 \\
\hline 8 & 9 & 1669 & 0.78 & 2078 & 1669 & 16.87 & 0 \\
\hline 9 & 10 & 1613 & 1.64 & 1960 & 1613 & 100.65 & 0 \\
\hline 10 & 11 & 1755 & 2.00 & 2349 & 1755 & 119.82 & 0 \\
\hline 11 & 12 & 1979 & 6.74 & 2711 & 1979 & 124.03 & 0 \\
\hline 12 & 13 & 2097 & 26.21 & 2375 & 2097 & 132.90 & 0 \\
\hline 13 & 14 & 2447 & 30.17 & 2625 & 2447 & 150.35 & 0 \\
\hline 14 & 15 & 2452 & 32.75 & 2823 & 2452 & 153.55 & 0 \\
\hline 15 & 20 & 3421 & 149.76 & 3665 & 3421 & 168.14 & 0 \\
\hline 16 & 25 & 4034 & 2940.05 & 5013 & 4034 & 301.45 & 0 \\
\hline 17 & 30 & 5415 & 12175.46 & 7273 & 5415 & 379.45 & 0 \\
\hline 18 & 35 & 6076 & 20292.51 & 7282 & 6152 & 483.45 & 1.25 \\
\hline 19 & 40 & 6821 & 91433.76 & 7518 & 7075 & 513.01 & 3.72 \\
\hline
\end{tabular}

It can be seen in Column 4 of Table 3 that the computation time of CPLEX increases significantly as the problem size increases. As noted, experiment 19 took CPLEX over 25 hours to obtain the optimal solution. For this reason, CPLEX runs were limited to 4 hours for largesized problems, shown in Table 4. The first column of Table 4 shows the experiment number. The second column shows the problem size in terms of number of job nodes. The CPLEX incumbent solution at the end of the 4-hour run is reported in the third column. An "N/A" in the 
third column indicates that CPLEX was not able to obtain a solution. The fourth column shows the objective function value of the initial feasible solution. The fifth column shows the RTS objective function value, and the sixth column shows the RTS computation time. The last column shows the gap between the CPLEX and RTS solutions. As indicated by the negative gap values, the RTS solutions for experiments 20 to 24 were lower (better) than the CPLEX solutions. It should be noted that a reason why CPLEX did not perform as well is due to the time limit. For very large problems (experiments 25 to 27), CPLEX could not find a solution due to either time limit or memory limit. The results in Table 4 verified that the developed integrated model is solvable by RTS within reasonable time for operational problems. The largest problem (experiment 27) with 200 job nodes took RTS less than 34 minutes to obtain the solution; as noted, CPLEX was unable to obtain a solution for this problem due to time or memory limit.

Table 4 Comparison of RTS performance against CPLEX for large-sized problems.

\begin{tabular}{|c|c|c|c|c|c|c|}
\hline (1) & (2) & (3) & (4) & (5) & (6) & (7) \\
\hline \multirow{3}{*}{$\begin{array}{l}\text { Experiment } \\
\text { No. }\end{array}$} & Problem & CPLEX & \multicolumn{3}{|c|}{ Solution method } & \\
\hline & size & & $\begin{array}{c}\text { Initial } \\
\text { feasible } \\
\text { solution }\end{array}$ & RTS & & \\
\hline & & $\begin{array}{c}\text { Objective } \\
\text { value }\end{array}$ & $\begin{array}{c}\text { Objective } \\
\text { value }\end{array}$ & $\begin{array}{c}\text { Objective } \\
\text { value }\end{array}$ & Time (s) & $\begin{array}{l}\text { Gap }^{1} \\
(\%)\end{array}$ \\
\hline 20 & 45 & 7932 & 8602 & 7296 & 535.15 & -8.02 \\
\hline 21 & 60 & 11000 & 11849 & 10270 & 765.92 & -6.64 \\
\hline 22 & 80 & 16010 & 16925 & 15520 & 895.37 & -3.06 \\
\hline 23 & 100 & 18927 & 19279 & 17927 & 1024.98 & -5.28 \\
\hline 24 & 120 & 22943 & 23277 & 21121 & 1375.69 & -7.94 \\
\hline 25 & 150 & N/A & 31200 & 28819 & 1699.80 & N/A \\
\hline 26 & 180 & N/A & 33744 & 30804 & 1874.25 & N/A \\
\hline 27 & 200 & N/A & 37910 & 36143 & 2003.24 & N/A \\
\hline
\end{tabular}

The sensitivity of the drayage operation time to various problem characteristics (e.g. appointment quotas in each time period, gate queuing time, and truck depot locations) was analyzed via a series of experiments. The effect of appointment quotas on the objective function 
values are summarized in Table 5. The test problems for these experiments consist of problems with 50, 60 and 70 job nodes. The first column in the Table 5 shows the experiment number, and the second column shows the problem size. The third column shows the set of appointment quotas. The forth column reports results obtained from RTS which are the set of booked appointments and the last column reports the objective function values. The solutions for experiments 28, 37 and 46 (will be referred to as base experiments) indicated that the number of booked appointments in the sixth and tenth time periods is equal to the set quotas, and thus, these quotas could potentially prevent the drayage firms from improving their operation time. To test how sensitive the objective function values are to these quotas, 8 different variations of appointments quotas were tested, as outlined below.

Quota variations from base experiment

1: Increase quota by 1 in the sixth time period

2: Increase quota by 2 in the sixth time period

3: Decrease quota by 1 in the sixth time period

4: Decrease quota by 2 in the sixth time period

5: Increase quota by 1 in the sixth and tenth time periods

6: Increase quota by 2 in the sixth and tenth time periods

7: Decrease quota by 1 in the sixth and tenth time periods

8: Decrease quota by 2 in the sixth and tenth time periods

Experiments 29 to 36 are the variations of base experiment 28. Experiments 38 to 45 are the variations of base experiment 37 , and experiments 47 to 54 are the variations of base experiment 46 . 
Table 5 Effect of appointment quotas on drayage operation time.

\begin{tabular}{|c|c|c|c|c|}
\hline $\begin{array}{c}\text { Experiment } \\
\text { No. }\end{array}$ & $\begin{array}{l}\text { Problem } \\
\text { size }\end{array}$ & $\begin{array}{c}\text { Set of } \\
\text { appointment quotas }\end{array}$ & $\begin{array}{c}\text { Set of } \\
\text { booked appointments }\end{array}$ & $\begin{array}{c}\text { Objective } \\
\text { value }\end{array}$ \\
\hline 28 & & $(10,10,10,10,10,10,10,10,10,10)$ & $(0,2,9,2,8,10,6,1,2,10)$ & 10092 \\
\hline 29 & & $(10,10,10,10,10, \underline{11}, 10,10,10,10)$ & $(0,6,6,2,5,11,7,2,1,10)$ & 9984 \\
\hline 30 & & $(10,10,10,10,10, \underline{12}, 10,10,10,10)$ & $(0,6,2,7,6,12,4,3,2,8)$ & 9899 \\
\hline 31 & & $(10,10,10,10,10, \underline{9}, 10,10,10,10)$ & $(0,6,5,1,7,9,6,3,3,10)$ & 10161 \\
\hline 32 & 50 & $(10,10,10,10,10, \underline{8}, 10,10,10,10)$ & $(0,6,3,4,9,8,5,2,3,10)$ & 10220 \\
\hline 33 & & $(10,10,10,10,10, \underline{11}, 10,10,10, \underline{11})$ & $(0,4,7,2,4,11,5,3,4,10)$ & 9955 \\
\hline 34 & & $(10,10,10,10,10, \underline{12}, 10,10,10, \underline{12})$ & $(0,5,6,2,4,12,3,3,5,10)$ & 9850 \\
\hline 35 & & $(10,10,10,10,10, \underline{9}, 10,10,10, \underline{9})$ & $(0,8,2,4,10,9,3,5,0,9)$ & 10201 \\
\hline 36 & & $(10,10,10,10,10, \underline{8}, 10,10,10, \underline{8})$ & $(0,4,3,5,9,8,6,5,2,8)$ & 10300 \\
\hline 37 & & $(10,10,10,10,10,10,10,10,10,10)$ & $(0,6,6,2,9,10,10,4,3,10)$ & 11574 \\
\hline 38 & & $(10,10,10,10,10, \underline{11}, 10,10,10,10)$ & $(0,6,6,2,8,11,9,4,4,10)$ & 11445 \\
\hline 39 & & $(10,10,10,10,10, \underline{12}, 10,10,10,10)$ & $(0,6,6,3,8,12,8,4,3,10)$ & 11309 \\
\hline 40 & & $(10,10,10,10,10, \underline{9}, 10,10,10,10)$ & $(0,7,4,5,10,9,7,5,3,10)$ & 11658 \\
\hline 41 & 60 & $(10,10,10,10,10, \underline{8}, 10,10,10,10)$ & $(0,7,5,5,8,8,10,5,3,9)$ & 11853 \\
\hline 42 & & $(10,10,10,10,10, \underline{11}, 10,10,10, \underline{11})$ & $(0,5,7,6,5,11,4,6,5,11)$ & 11365 \\
\hline 43 & & $(10,10,10,10,10, \underline{12}, 10,10,10, \underline{12})$ & $(0,5,5,7,6,12,5,7,2,11)$ & 11289 \\
\hline 44 & & $(10,10,10,10,10, \underline{9}, 10,10,10, \underline{9})$ & $(0,2,9,4,8,9,10,4,5,9)$ & 11699 \\
\hline 45 & & $(10,10,10,10,10, \underline{8}, 10,10,10, \underline{8})$ & $(0,4,6,5,8,8,10,5,6,8)$ & 11995 \\
\hline 46 & & $(10,10,10,10,10,10,10,10,10,10)$ & $(0,10,5,8,10,10,5,5,7,10)$ & 14500 \\
\hline 47 & & $(10,10,10,10,10, \underline{11}, 10,10,10,10)$ & $(0,6,9,6,10,11,9,7,4,8)$ & 14456 \\
\hline 48 & & $(10,10,10,10,10, \underline{12}, 10,10,10,10)$ & $(0,10,5,6,8,12,6,5,8,10)$ & 14211 \\
\hline 49 & & $(10,10,10,10,10, \underline{9}, 10,10,10,10)$ & $(0,7,9,6,10,9,9,6,4,10)$ & 14551 \\
\hline 50 & 70 & $(10,10,10,10,10, \underline{8}, 10,10,10,10)$ & $(0,7,8,7,10,8,10,6,4,10)$ & 14701 \\
\hline 51 & & $(10,10,10,10,10, \underline{11}, 10,10,10, \underline{11})$ & $(0,8,7,7,9,11,6,8,3,11)$ & 14441 \\
\hline 52 & & $(10,10,10,10,10, \underline{12}, 10,10,10, \underline{12})$ & $(0,10,6,4,10,12,9,3,4,12)$ & 14105 \\
\hline 53 & & $(10,10,10,10,10, \underline{9}, 10,10,10, \underline{9})$ & $(0,6,10,6,10,9,5,8,8,8)$ & 14637 \\
\hline 54 & & $(10,10,10,10,10, \underline{8}, 10,10,10, \underline{8})$ & $(0,10,7,6,10,8,10,6,5,8)$ & 14854 \\
\hline
\end{tabular}

From the sensitivity analysis results (Table 5), higher appointment quotas via variations $1,2,5$, or 6 led to a reduction in the objective function values and thus more efficient drayage schedules. For example, for variation 6, compared to the base experiments the objective function value for experiment 34 decreased by 242 minutes $(2.40 \%)$, objective function value for 
experiment 43 decreased by 285 minutes (2.46\%), and objective function value for experiment 52 decreased by 395 minutes (2.72\%). Conversely, lower appointment quotas led to an increase in the objective function value and thus less efficient drayage schedules. For example, for variation 8, compared to the base experiments the objective function value for experiment 36 increased by 208 minutes (2.06\%), objective function value for experiment 45 increased by 421 (3.64\%), and objective function value for experiment 54 increased by 354 minutes (2.44\%).

Comparing the results of those experiments with 50, 60, and 70 job nodes (see column 2 of Table 5), it was expected that the percentage of change in the objective function value will increase with problem size; however, that was not the case. For example, in experiment 45 (variation 8 ) with 60 job nodes, the objective function value increased by 421 minutes (3.64\%), whereas in experiment 54 (variation 8) with 70 job nodes the objective function value increased by 354 minutes $(2.44 \%)$. According to the results, for a given increase or decrease in quota, there appears to be no correlation between problem size and percentage of change in objective function value.

Figure 9a illustrates the relationship between the objective function value and change in appointment quotas (variations 1 to 4 ) for three problem size (50, 60, and 70 job nodes). Figures $9 \mathrm{~b}, 9 \mathrm{c}$, and $9 \mathrm{~d}$ show the same results for each problem size in a finer scale. The shown graphs indicate that as the appointment quotas are increased, the objective function value will decrease; however, this trend is not linear. These results suggest that drayage operation time is affected not just by the appointment quotas, but also perhaps by other operational constraints such as time windows at customers' locations, travel time, and location of empty container depot and truck depot. Figures 9b, 9c and 9d also shows the results of variations 5 and 7 , denoted as asterisks. This is intended to compare the effect of increasing or decreasing two appointment quotas in one 
time period (variations 2 and 4) vs. increasing or decreasing one appointment quota in two different time periods (variations 5 and 7). It can be concluded that decreasing two appointment quotas in one time period has more negative effect on the objective function value than decreasing one appointment quota in two different time periods. Conversely, increasing two appointment quotas in one time period has more positive effect on the objective function value than increasing one appointment quota in two different time periods. These results suggest that in increasing or decreasing the appointment quotas, not only are their values important but also how they are distributed among the time periods.

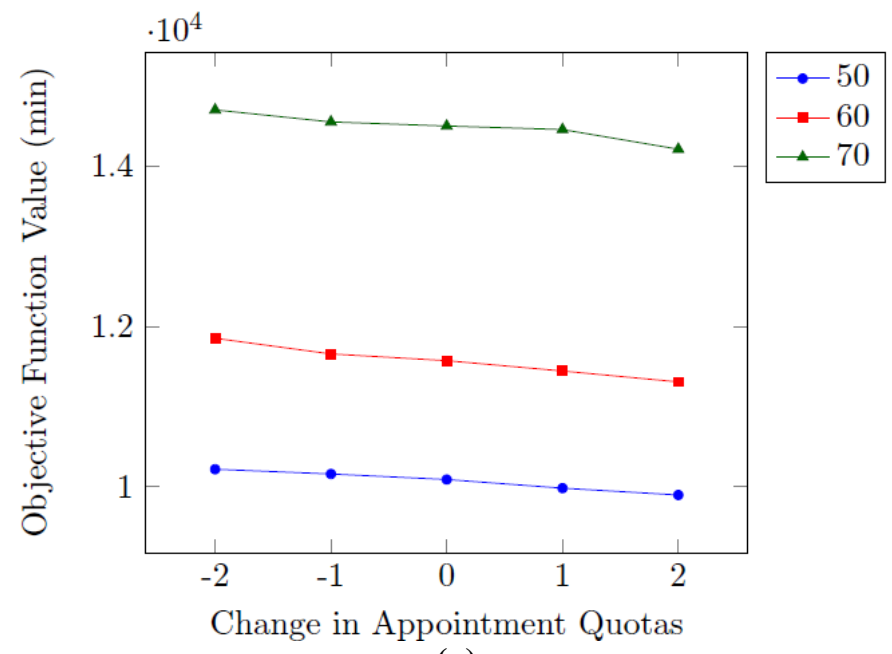

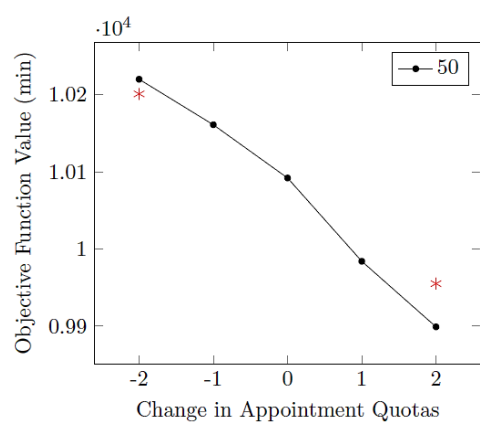

(b)

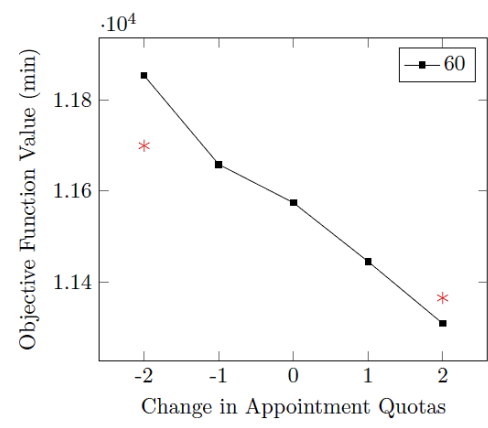

(c)

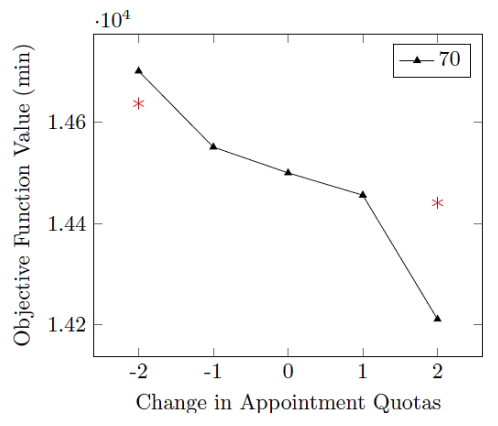

(d)

Figure 9 Effect of change in number of appointment quotas on objective function value.

To test the effect of gate queuing time on drayage operation time, two different queuing times were used: 2 and 20 minutes; these numbers represent an ideal gate queuing time with the truck appointment system implemented and a typical gate queuing time. The test problems for 
these experiments consist of problems with 50, 100, 150 and 200 job nodes (50\% import and $50 \%$ export). The results of this experiment are reported in Table 6. The first column shows the experiment number, and the second column shows the problem size. The third and fourth columns report the objective function values obtained from RTS for 20 and 2 minutes gate queuing time, respectively. The results indicate a reduction in gate queueing time from 20 to 2 minutes will reduce the drayage operation time. The reduction in objective function value ranges from 3.27 hours $(2.19 \%$ ) (in experiment 55) to 28.03 hours (4.63\%) (in experiment 58). The results correspond to intuition that shorter gate queuing time will lead to a more efficient drayage operation. They highlight the fact that if terminal operators schedule trucks at the terminal in a manner that maximizes the effectiveness of appointment systems, then the negative effect of the appointment system on drayage firm will diminish as a result of reducing truck queuing/idling time. In addition, these findings can help terminal operators in setting up the appointment system by giving them insight into the effect of different queuing time on drayage firms.

Table 6 Effect of gate queuing time on drayage operation time.

\begin{tabular}{|c|c|c|c|}
\hline \multirow{2}{*}{$\begin{array}{l}\text { Experiment } \\
\text { No. }\end{array}$} & \multirow{2}{*}{$\begin{array}{c}\text { Problem } \\
\text { size }\end{array}$} & \multicolumn{2}{|c|}{ Gate queuing times } \\
\hline & & $\begin{array}{c}20 \\
(\mathrm{~min})\end{array}$ & $\begin{array}{c}2 \\
(\mathrm{~min})\end{array}$ \\
\hline 55 & 50 & 8955 & 8759 \\
\hline 56 & 100 & 19327 & 18329 \\
\hline 57 & 150 & 26078 & 24961 \\
\hline 58 & 200 & 36309 & 34627 \\
\hline
\end{tabular}

The final set of experiments was conducted to investigate the impact of truck depot location on drayage operation time. For this experiment, a network with only one truck depot is used. Locations A, B and C in Figure 10a are three candidate locations for the truck depot. Locations $\mathrm{B}$ and $\mathrm{C}$ are closer to the terminal than location $\mathrm{A}$, and they both have the same travel time to the terminal, but location $\mathrm{C}$ is 20 minutes closer to the empty container depot. The test 
problems for this experiment consist of 50 import and 50 export job nodes (at random locations). Figure $9 \mathrm{~b}$ shows the relationship between the objective function value and the location of truck depot. It can be seen in the graph that changing the truck depot location from $\mathrm{A}$ to $\mathrm{C}$ reduced the objective function value by about $6.13 \%$. This finding suggests that a truck depot closer to both the terminal and empty container depot will benefit the drayage operations. This result makes sense since all routes must begin from the truck depot to either the empty container depot (to pick up an empty container) or the terminal (to pick up a full container) and end with the truck traveling from either the empty container depot (after dropping off an empty container) or the terminal (after dropping off a full container) to the truck depot. It can be generalized from these results that the location of the truck depot has an effect on drayage operation time; the closer it is to the terminal and empty container depot the better, regardless of where customers are located in the network.

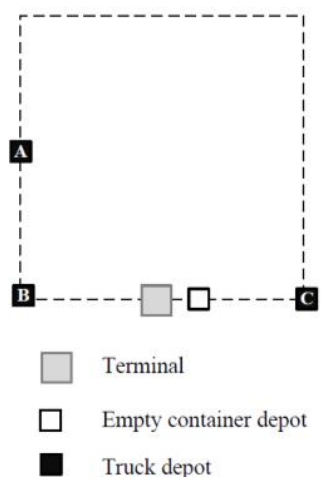

(a)

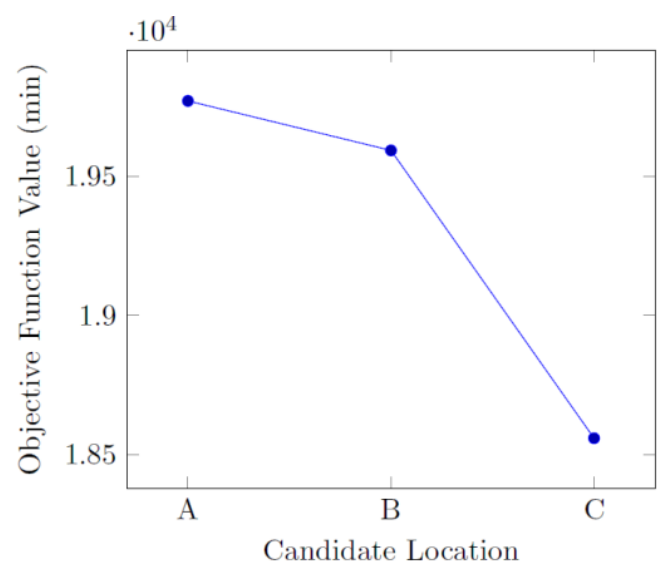

(b)

Figure 10 (a) Candidate locations for truck depot; (b) Effect of truck depot location on drayage operation time.

\section{Conclusion}

This paper addressed the challenge posed to drayage firms of having to make appointments at terminals in advance. In this emerging practice, drayage firms need to make scheduling 
decisions while complying with the terminal-specified truck appointment system. To address this problem, a mixed-integer programming model was developed to solve the empty container allocation problem, vehicle routing problem and appointment booking problem in an integrated manner. A reactive tabu search algorithm (RTS) combined with a greedy algorithm was developed to solve the integrated optimization model. To demonstrate the feasibility of the developed model and solution methodology, they are tested on a hypothetical network via a series of experiments with real life characteristics. The RTS solutions demonstrated that the developed integrated model is capable of finding the optimal solutions and is solvable within reasonable time for an operational problem.

The developed integrated model allowed for the evaluation of the effect of the truck appointment system on drayage operations. Experimental results indicated that 1) the appointment quota per time period set by the terminal operator has a significant effect on drayage operation time (the objective function value decreases as the quota increases, but the trend is not linear), 2) for a given change in appointment quota, there is no correlation between problem size and percentage of change in objective function value, 3) the drayage firms could benefit considerably with an efficient truck appointment system that minimizes gate queuing/idling time, and 4) truck depots should be sited close to the terminal and empty container depot.

This study has a few limitations that need to be taken in account when interpreting the aforementioned results. First, the drayage problem was treated as a static and deterministic problem, and hence, it did not account for traffic congestion, accidents, and other unexpected delays that would result in trucks potentially missing appointments. Second, it did not consider cases where trucks need to be rerouted due to accidents. Third, this study assumed that the truck 
turn time at the terminal is deterministic. Lastly, it should be noted that these results are based on a hypothetical network with a single drayage firm. Future research in this area could seek to improve on the aforementioned four limitations, as well as consider a centralized approach to optimize the truck appointment system for both the terminal operator and drayage firms. In addition, future research could seek to use more intricate truck appointment system features as outlined in the work by Huynh et al. (2016).

\section{Acknowledgement}

This paper is based upon work supported by the National Science Foundation under Grant No. 1100227.

\section{References}

Battiti, R., Tecchiolli, G., 1994. The reactive tabu search. ORSA Journal on Computing 6 (2), 126- 140 .

Braekers, K., Caris, A., Janssens, G.K., 2013. Integrated planning of loaded and empty container movements. OR Spectrum, 35(2), 457-478.

Braekers, K., Caris, A., Janssens, G.K., 2014. Bi-objective optimization of drayage operations in the service area of intermodal terminals. Transportation Research Part E 65, 50-69.

Braekers, K., Janssens, G. K., Caris, A., 2011. Challenges in managing empty container movements at multiple planning levels. Transport Reviews 31(6), 681-708.

Caris, A., Janssens, G. K., 2009. A local search heuristic for the pre-and end-haulage of intermodal container terminals. Computers and Operations Research 36, 2763-2772. 
Chen, G., Govindan, K., Yang, Z. Z., Choi, T. M., Jiang, L., 2013. Terminal appointment system design by non-stationary $\mathrm{M}(\mathrm{t}) / \mathrm{Ek} / \mathrm{c}(\mathrm{t})$ queueing model and genetic algorithm. Int. J. Production Economics 146, 694-703.

Chen, G., Yang, Z., 2010. Optimizing time windows for managing export container arrivals at Chinese container terminals. Maritime Economics and Logistics, 12(1), 111-126.

Chen, G., Yang, Z., Jiang, L., 2010. Reducing marine container terminal gate congestion with vessel-dependent time windows for truck entries. Transportation Research Board $89^{\text {th }}$ Annual Meeting (No. 10-0545).

Cheung, R. K., Hange, D. D., 2003. A time-window sliding procedure for driver-task assignment with random service times. IIE Transactions 35, 433-444.

Chiang, W. C., Russell, R. A., 1997. A reactive tabu search metaheuristic for the vehicle routing problem with time windows. INFORMS Journal on Computing 9 (4), 417-430.

Chung, K. H., Ko, C. S., Shin, J. Y., Hwang, H., Kim, K. H., 2007. Development of mathematical models for the container road transportation in Korean trucking industries. Computers and Industrial Engineering 53, 252-262.

Crainic, T. G., Gendreau, M., Dejax, P., 1993. Dynamic and stochastic models for the allocation of empty Dynamic and stochastic models for the allocation of empty. Operation Research 41 (1), 102-126.

Escudero, A., Muñuzuri, J., Arango, C., Onieva, L., 2011. A satellite navigation system to improve the management of intermodal drayage. Advanced Engineering Informatics 25, 427434.

Escudero, A., Muñuzuri, J., Guadix, J., Arango, C., 2013. Dynamic approach to solve the daily drayage problem with transit time uncertainty. Computers in Industry 64, 165-175. 
Huynh, N., Smith, D., Harder, F., 2016. Truck appointment systems: where we are and where to go from here. Transportation Research Board $95^{\text {th }}$ Annual Meeting (No. 16-5663)

Imai, A., Nishimura, E., Current, J., 2007. A Lagrangian relaxation-based heuristic for the vehicle routing with full container load. European Journal of Operational Research 176, 87105.

Jula, H., Dessouky, M., Ioannou, P., Chassiakos, A., 2005. Container movement by trucks in metropolitan networks: modeling and optimization. Transportation Research Part E 41, 235259.

Máhr, T., Srour, J., Weerdt, M. d., Zuidwijk, R., 2010. Can agents measure up? A comparative study of an agent-based and on-line optimization approach for a drayage problem with uncertainty. Transportation Research Part C 18, 99-119.

Morlok, E. K., Spasovic, L. N., 1994. Approaches for improving drayage in rail-truck intermodal service. https://transportation.njit.edu/NCTIP/final_report/approaches_for_ improving_ drayage.htm.

Namboothiri, R., Erera, A. L., 2008. Planning local container drayage operations given a port access appointment system. Transportation Research Part E 44, 185-202.

NCFRP Report 11, 2011. Truck Drayage productivity guide. Transportation Research Board of the National Academies, Washington, D.C.

Osman, I. H., 1993. Metastrategy simulated annealing and tabu search algorithms for the vehicle routing problem. Annals of Operations Research 41, 421-451.

Osman, I. H., Wassan, N. A., 2002. A reactive tabu search meta-heuristic for the vehicle routing problem with back-hauls. Journal of Scheduling, 5(4), 263-285. 
Popović, D., Vidović, M., Nikolić, M., 2014. The variable neighborhood search heuristic for the containers drayage problem with time windows. Soft Computing in Industrial Applications $223,351-364$.

Smilowitz, K., 2006. Multi-resource routing with flexible tasks: an application in drayage operations. IIE Transactions 38, 555-568.

Smith, D., Harder, F., Huynh, N., Hutson, N., Harrison, R., 2012. Analysis of current and emerging drayage practices. Transportation Research Record: Journal of the Transportation Research Board 2273, 69-78.

Sterzik, S., Kopfer, H., Yun, W. Y., 2015. Reducing hinterland transportation costs through container sharing. Flexible Services and Manufacturing Journal 27 , 382-402.

Wang, X., Kopfer, H., 2015. Rolling horizon planning for a dynamic collaborative routing problem with full-truckload pickup and delivery requests. Flexible Services and Manufacturing Journal, 1-25.

Wang, X., Regan, A. C., 2002. Local truckload pickup and delivery with hard time window constraints. Transportation Research Part B 36, 97-112.

Wassan, N. A., Wassan, A. H., Nagy, G., 2008. A reactive tabu search algorithm for the vehicle routing problem with simultaneous pickups and deliveries. Journal of Combinatorial Optimization 15, 368-386.

Woodruff, D. L., Zemel, E., 1993. Hashing vectors for tabu search. Annals of Operations Research 41, 123-137.

Xue, Z., Zhang, C., Lin, W. H, Miao, L., Yang, P., 2014. A tabu search heuristic for the local container drayage problem under a new operation mode. Transportation Research Part E 62, 136-150. 
Zhang, G., Smilowitz, K., Erera, A., 2011. Dynamic planning for urban drayage operations. Transportation Research Part E 47, 764-777.

Zhang, R., Yun, W. Y., Kopfer, H., 2010. Heuristic-based truck scheduling for inland container transportation. OR Spectrum 32, 787-808.

Zhang, R., Yun, W. Y., Kopfer, H., 2015. Multi-size container transportation by truck: modeling and optimization. Flexible Services and Manufacturing Journal 27 , 403-430.

Zhang, R., Yun, W. Y., Moon, I., 2009. A reactive tabu search algorithm for the multi-depot container truck transportation problem. Transportation Research Part E 45, 904-914.

Zhang, R., Yun, W. Y., Moon, I. K., 2011. Modeling and optimization of a container drayage problem with resource constraints. Int. J. Production Economics 133, 351-359. 